\title{
Investigation of Work Hardening Behavior of Inconel X-750 Alloy
}

\author{
Pei-Tao Hua $^{1,2} \cdot$ Wei-Hong Zhang ${ }^{1} \cdot$ Lin-Jie Huang ${ }^{1,2} \cdot$ Wen-Ru Sun ${ }^{1}$
}

Received: 3 March 2017/Revised: 12 May 2017/Published online: 30 June 2017

(C) The Chinese Society for Metals and Springer-Verlag GmbH Germany 2017

\begin{abstract}
The constant strain rate uniaxial compression tests were conducted in this paper for studying the work hardening behavior and revealing the underlying microstructure evolution involved in the plastic response of the nickel-based Inconel X-750 alloy. The work hardening rate versus true strain plots of Inconel X-750 alloy resembled that of low-stacking-fault energy (SFE) alloys with distinct four stages. The dislocations were found in the planar arrangements at a strain of 0.1 located at the onset of stage II, and the dislocation density was increased and the planar arrangement configuration was partially destroyed at a strain of 0.36 located in stage III. It was unexpected that deformation twins were observed at a strain of 0.69 located in stage IV although the alloy has been classified into materials with a higher SFE value. The result is different with a similar study, in which the deformation twins were absent in Ni-Cr-based alloy Inconel 625 even when the strain was as high as 0.65 . It was deemed that the low level of solution strengthening favored the deformation of matrix and the activation of slip system for twining in Inconel X-750 alloy. Unlike the low-SFE alloys that the twins were always formed at the end of stage I, the higher SFE delayed the twin formation to stage IV for Inconel X-750 alloy. The welldeveloped planar dislocation configuration gave rise to the stage II with a slightly decreasing rate, the collapse of planar dislocation arrangements caused the occurrence of stage III with an accelerated decreasing rate, and the twin formation led to the stage IV with a nearly constant work hardening rate.
\end{abstract}

\section{KEY WORDS: Inconel X-750 alloy; Work hardening behavior; Planar dislocation arrangement; Deformation} twins

\section{Introduction}

Revealing the relationship between the mechanical behavior and the intrinsic microstructure in alloys is always an interesting issue and of great value for the

Available online at http://link.springer.com/journal/40195

Wen-Ru Sun

wrsun@imr.ac.cn

1 Superalloys Division, Institute of Metal Research, Chinese Academy of Sciences, 110016 Shenyang, China

2 University of Chinese Academy of Sciences, 100049 Beijing, China industry manufacturing. In general, it is known that the rate of work hardening continuously decreases with the increase in strain when the dislocation slip dominates the plastic deformation in high-SFE face-centered crystal (fcc) alloys. The deformation twins, however, were confirmed to play a key role in the strain hardening behavior of the fcc alloys [1-7]. The work hardening behaviors of MP35 $\mathrm{N}$ alloy and $\boldsymbol{\alpha}$-brass with low SFE were investigated together with copper with high SFE [2]. The strain hardening rate was normalized with shear modulus $(G)$ and plotted against both $\left(\sigma-\sigma_{\mathrm{YS}}\right) / \mathrm{G}\left(\sigma_{\mathrm{YS}}\right.$ being the initial yield strength of the alloy) and plastic strain $\varepsilon_{\mathrm{p}}$. Such normalized plots for MP35 N and $\alpha$-brass were found to be almost identical to each other and revealed four distinct stages of strain hardening: stage A, with a 
steadily decreasing strain hardening rate up to a true strain of about 0.08 ; stage $\mathrm{B}$, with an almost constant strain hardening rate up to a true strain of about 0.2 ; stage $\mathrm{C}$, with a steadily decreasing strain hardening rate up to a true strain of about 0.55 ; and a final stage $\mathrm{D}$, again with an almost constant strain hardening rate. Deformation twins were found at the onset of stage $\mathrm{B}$ and dominated the characteristics of the stages B, C and D. While the work hardening rate of copper with high SFE was distinctly different from that of MP35 N and $\alpha$-brass, it decreased simply with increasing $\varepsilon_{\mathrm{p}}$. Many similar results have been recorded, for example, the work hardening behavior of low-SFE alloys such as $\mathrm{Cu}-\mathrm{Al}$ alloys [4, 7-10], austenitic stainless steels [5] and twinning-induced plasticity steels [11] resembled that of MP35 N and $\alpha$-brass, and the work hardening behavior of the high-SFE alloys was mostly alike that of copper [1]. However, the value of SFE might not be the only element that dominates the different work hardening behaviors of all of the alloys, exceptions were observed in some nickel-based superalloy such as Inconel 600 [12], Inconel 625 [13] and Inconel X-750 [14]. Though these alloys presented similar curves of work hardening rates versus $\varepsilon_{\mathrm{p}}$, with distinct three or four stages characteristic, the deformation twins were found in MP35 $\mathrm{N}$ alloy at a strain of 0.14 [2], while not in Inconel 625 alloy at a strain up to 0.65 [13]. So the microstructure evolution of the Ni-Cr-based alloy should be investigated further in detail to understand the relationship between the deformation mechanism and the work hardening behavior of these alloys.

Inconel X-750 is an age-hardenable alloy and exhibits excellent mechanical strength, fatigue resistance and hot corrosion resistance [15]. This superalloy has a wide field of applications including gas turbine, rocket engine, aircraft structures, forming tools, pressure vessel and nuclear reactors $[14,16-20]$. The work hardening behavior of Inconel X-750 alloy has been studied extensively [14, 20]. Although the SFE was estimated to be around $90 \mathrm{~mJ} / \mathrm{m}^{2}$ at the annealed state [21], its hardening behavior was similar with the alloys with low SFE, and no detail deformation microstructures were observed in its deformed structures. In addition, the previous investigations were mostly limited to a lower strain due to the necking initiated at the earlier stage of deformation and hence the work hardening behavior, and the deformation mechanism at large strain is not known till now.

The aim of the present paper is to investigate the work hardening behavior of Inconel X-750 alloy up to a large strain by means of simple compression, and the microstructure evolution is observed carefully to obtain a deeper view on the work hardening behavior of the alloy.

\section{Experimental}

The chemical composition of the alloy (in wt $\%$ ) is $15.4 \mathrm{Cr}$, 7.0Fe, 2.5 Ti, 0.9Al, $1.0 \mathrm{Nb}, 0.05 \mathrm{C}, 0.1 \mathrm{Mn}, 0.1 \mathrm{Si}, 0.045 \mathrm{Co}$, $0.016 \mathrm{Cu}$ and $\mathrm{Ni}$ balance. Cylindrical Inconel X-750 samples with $6 \mathrm{~mm}$ diameter and $9 \mathrm{~mm}$ height were machined from the annealed rods which were treated at $980{ }^{\circ} \mathrm{C}$ for $30 \mathrm{~min}$, in order to obtain a fully recrystallized microstructure, with an average grain sizes around $28 \mu \mathrm{m}$. To investigate the work hardening behavior and microstructural evolution, constant strain rate uniaxial compression tests were performed on the computer-controlled Gleeble-3800 testing system at room temperature (RT) with strain rates of $0.001,0.5$ and $5 \mathrm{~s}^{-1}$. The flow stress-strain curves were obtained by employing the classical equations for compression tests. The deformed specimens were sectioned parallel to the compression axis along a diameter, and the cut surfaces were mechanically polished using standard techniques and etched at $10 \mathrm{~V}$ for about $30 \mathrm{~s}$ in a solution containing $10 \mathrm{gC}_{2} \mathrm{H}_{2} \mathrm{O}_{4^{-}}$ $2 \mathrm{H}_{2} \mathrm{O}+100 \mathrm{ml} \mathrm{H}_{2} \mathrm{O}$. In addition, samples of annealed Inconel X-750 deformed to different true strain levels were prepared for SEM and TEM observation. Slices about $0.4 \mathrm{~mm}$ in thickness were cut transverse to the loading direction using an electro-discharge machine and then ground to a thickness of about $0.06 \mathrm{~mm}$. Disks of $3 \mathrm{~mm}$ diameter were punched from the ground slices. The TEM thin foils were prepared using a solution of $20 \%$ perchloric acid in methanol at $-26{ }^{\circ} \mathrm{C}$, with an operative voltage of 24 V. TEM observations were carried out on a JEOL 2010 electron microscope operating at $200 \mathrm{kV}$.

\section{Results}

\subsection{Work Hardening Behavior}

Figure 1a shows the true stress-true strain responses of the alloy compressed to 1.2 at room temperature under true strain rates of 0.001 and $0.5 \mathrm{~s}^{-1}$ and to 0.9 at strain rate of $5 \mathrm{~s}^{-1}$. An increase in the stress was observed when the strain rate was increased from 0.001 to $0.5 \mathrm{~s}^{-1}$, which means a positive work hardening sensibility with the strain rate. While the stress-strain curves were only slightly shifted when the strain rate was raised from 0.5 to $5 \mathrm{~s}^{-1}$, the true stress was initially dramatically increased as the strain increased with little magnitude, which was known as the elastic deformation stage. The yield stress $\sigma_{\mathrm{YS}}$ was estimated to be around $406 \mathrm{MPa}$ at 0.5 and $5 \mathrm{~s}^{-1}$ and $398 \mathrm{MPa}$ at $0.001 \mathrm{~s}^{-1}$. It is worth noticing that the magnitude of the true stress does not increase significantly at the large strain regime and the true stress appears to 

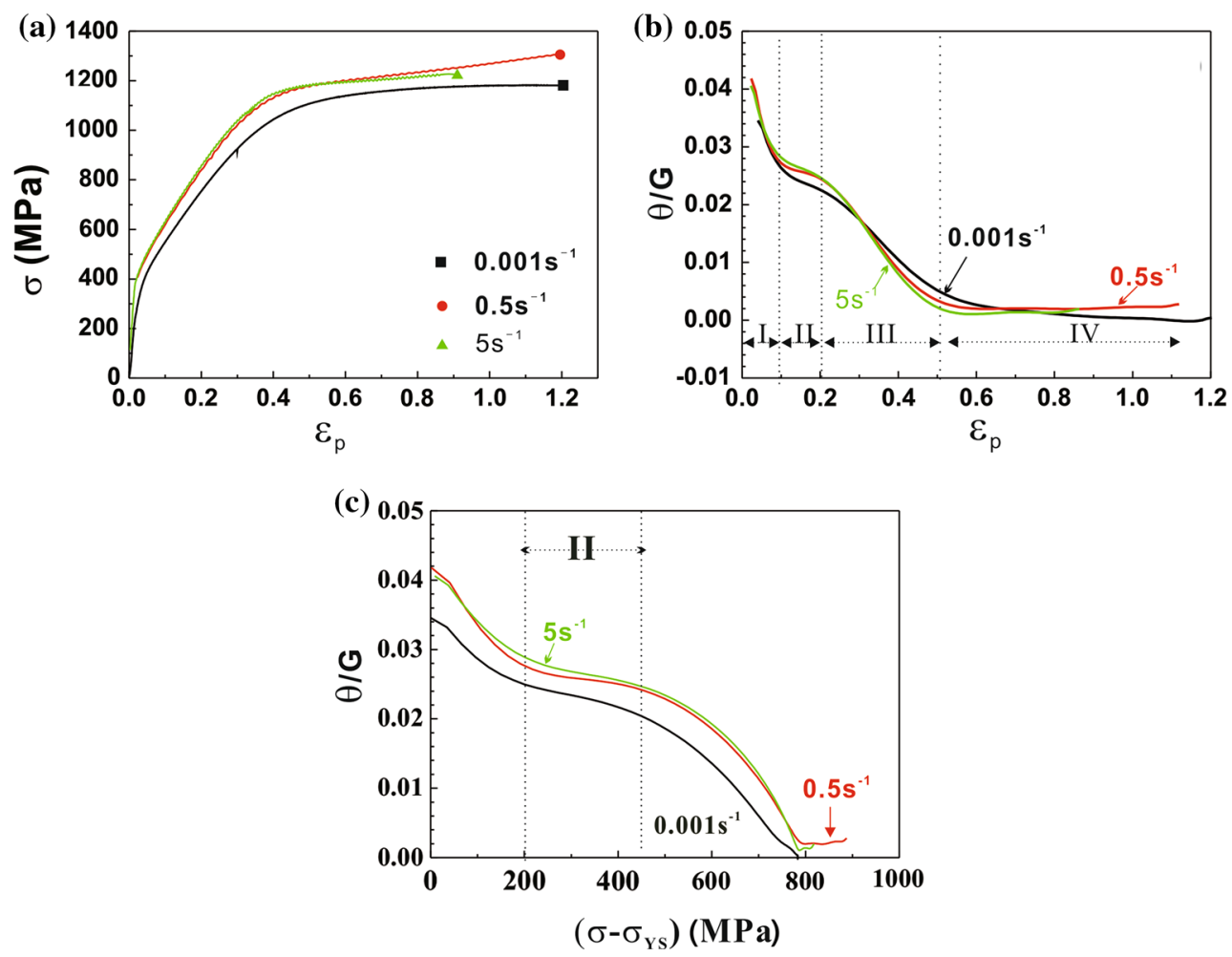

Fig. 1 a True stress-true strain response of Inconel X-750 alloy under different true strain rates at RT, b dependence of the strain hardening rate on the imposed plastic strain $\varepsilon_{\mathrm{p}}, \mathbf{c}$ dependence of the strain hardening rate on the $\left(\sigma-\sigma_{\mathrm{YS}}\right)$

asymptote to a saturated value, especially for the strain rate of $0.001 \mathrm{~s}^{-1}$, which was usually absent in the tensile tests, since the initiation of necking is unavoidable.

It should be mentioned that differentiation of the true stress-true strain curves is necessary to determine the value of work hardening rate $\theta$, but short-range noise can render such differentiation calculus impossible. In order to solve this problem, a smoothing by fitting a high-order polynomial to the flow curves was used to eliminate the irregularities and fluctuations in the experimental curves, with the elastic part removed. Therefore, a seventh- to ninthorder polynomial was applied in the paper to fit and smooth the flow curves [22]. Figure $1 \mathrm{~b}$ shows the variation of strain hardening rate (normalized with shear modulus $G$ about $84.5 \mathrm{GPa}$ [23]) with imposed plastic strain $\varepsilon_{\mathrm{p}}$ under different strain rates; four distinct regimes of work hardening are clearly indicated in these plots. For the strain hardening curve at $0.5 \mathrm{~s}^{-1}$, as shown in Fig. 1b, the normalized work hardening rate falls dramatically with the increasing strain during the first regime, stage I (Fig. 1b), which lasts up to a very small strain, about 0.10 . The stage II lies in the strain regime from 0.10 to 0.21 (Fig. 1b), with a slope much smaller than that of stage I. The stage III lies in the strain regime from 0.21 to 0.51 (Fig. 1b), and the slope of the curve becomes much larger again like that of stage I. The curve goes into stage IV when the strain exceeds 0.51 , and it becomes nearly flat which means that the strain hardening rate remains constant in this stage. The curves corresponding to the strain rates of 0.5 and $5 \mathrm{~s}^{-1}$ are very similar to each other and coincide well, while the work hardening rate at stage II of the curve at $0.001 \mathrm{~s}^{-1}$ is smaller, and both the initiation and termination strains in stage II are higher than those at 0.5 and $5 \mathrm{~s}^{-1}$.

Reed-Hill et al. [24] pointed out that different regimes of work hardening represented by work hardening rate $\theta$ versus strain plots were subjected to variations depending on the prior deformation history. They suggested that work hardening rate $\theta$ versus stress plots are more appropriate as various regimes of such plots are not influenced by the prior deformation history. More specifically, the flow stress contribution from dislocation $\sigma_{\mathrm{d}}$ is preferred [25, 26]. And in pure metals, the flow stress is given by the well-established relation [27]:

$\sigma=\sigma_{0}+M \alpha G b \rho^{1 / 2}$

where $\sigma_{0}$ is a friction stress, $M$ the Taylor factor, $b$ the Burgers vector, $G$ the shear modulus, $\alpha$ a constant, and $\rho$ the dislocation density. And the flow stress contribution from the dislocations $\sigma_{\mathrm{d}}$ is expressed as

$\sigma_{\mathrm{d}}=\sigma-\sigma_{0}=M \alpha G b \rho^{1 / 2}$.

The value of $\sigma_{0}$ has been determined using the yield stress $\sigma_{\mathrm{YS}}$. Figure 1c shows the dependence of the strain hardening rate $\theta$ on the $\left(\sigma-\sigma_{\mathrm{YS}}\right)$. The motivation for 
subtracting $\sigma_{\mathrm{YS}}$ from $\sigma$ is to isolate the contribution from dislocation multiplication from other mechanisms of hardening (e.g., solid solution hardening). Compared with $\theta / G$ versus $\varepsilon_{\text {p }}$ plots (Fig. 1b), stage II is more prominent, while stage IV seems to be vanished (Fig. 1c), which is reasonable since the magnitude of the true stress does not increase significantly at the large strain regime (Fig. 1a). And the strain hardening rate was demonstrated to be increased with increasing strain rate at stage II in the case.

\subsection{Microstructure Characterization}

The backscattered SEM images presented in Fig. 2a shows the microstructure of the Inconel X-750 superalloy at annealed state, annealing twins (highlighted by the yellow dash line) are distributed in the equiaxed grains, and blocky precipitates appeared occasionally which are the $(\mathrm{Nb}, \mathrm{Ti})$ carbides [20]. The TEM image in Fig. 2b shows that dislocations are absent in the matrix, indicating that the recrystallization has happened fully during annealing.

The microstructures of the specimens subjected to strains of $0.10,0.36,0.69$ and 1.2 at room temperature with the true strain rate of $0.5 \mathrm{~s}^{-1}$ were characterized to reveal the evolution of microstructure during deformation. Figure 3a shows the sample deformed to a true strain of 0.10 , near the end of the stage I and the onset of the stage II. Though the grains were slightly stretched, no deformation markings were observed in the sample deformed to 0.36 , as represented in Fig. 3b. Deformation markings, however, appeared in the sample deformed to a true strain of 0.69 in Fig. 3c. And this kind deformation markings were extensively observed when the true strain is added up to 1.2 , as shown in Fig. 3d. The grains were more severely elongated when the true strain was raised from 0.69 to 1.2 . And deformation markings were usually observed to stretch in one direction at the strain of 0.69 and the intersection of the deformation markings occurred in the sample compressed to 1.2. In other words, the grains were slightly stretched when the strain is less than 0.36 without deformation markings observed. Deformation markings were observed to be involved in the plastic deformation when the strain is higher than 0.69 .

At the early deformation with a true strain of 0.05 , planar arrangement of the dislocation was observed in Fig. 4, which means the planar slip domains the plastic deformation. Figure $5 \mathrm{a}$ shows the dislocation structures of Inconel X-750 at the true strain of 0.10, around the end of the stage I and the onset of the stage II. Planar arrangement of the dislocation, in the form of slip bands, is the main deformation microstructure feature which is in agreement with Thomas' observation [28]. It should be noticed that the activation of another set of planar dislocations was also observed as shown in Fig. 5b, which means that the deformation extent varies between different grains. It may be seen that spacing between these parallel slip bands is still obvious at the onset of the strain hardening stage II, which is rather narrower with further compression to 0.21 shown in Fig. 6. The typical dislocation structure of Inconel X-750 at the true strain of 0.36 in the regime of stage III is shown in Fig. 7. A high density of the dislocation with planar configuration is observed in Fig. 7a, and most of the planar dislocation arrays are intersected. The spacing between dislocation arrays is much narrower than that at lower strain level, and the planar configuration of the dislocations is partially destroyed, as shown in Fig. 7b. Figure $8 \mathrm{a}$ is the typical microstructural characteristic of the sample deformed to a true strain of 0.69 . High-density dislocations were separated into different regions by the deformation twins, with spacing around $500 \mathrm{~nm}$ between each other. The width of the deformation twins is about
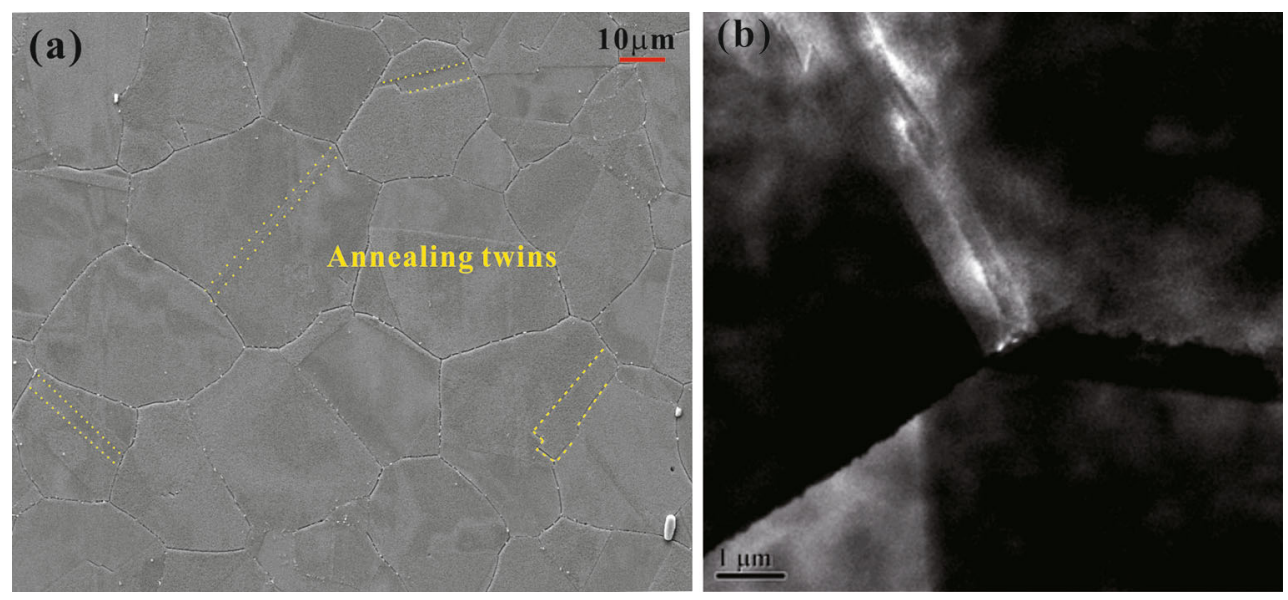

Fig. 2 Microstructures of the annealed samples, a BSED image showing equiaxed grains with annealing twins and the precipitates dispersed in the matrix, $\mathbf{b}$ TEM image of the $\gamma$ matrix absence of dislocations 

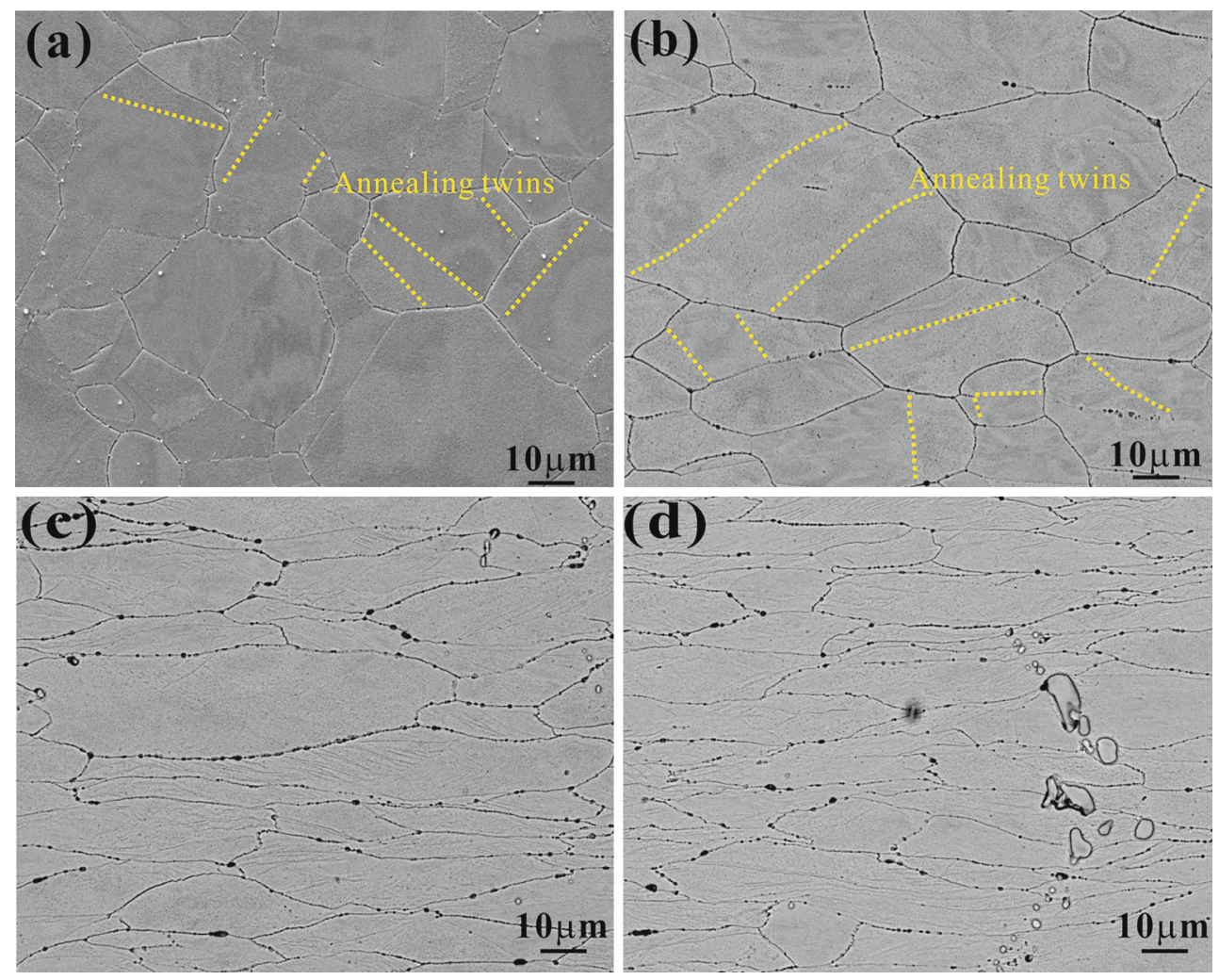

Fig. 3 BSED micrographs showing the evolution of the deformation microstructure in the Inconel X-750 alloy after uniaxial compression to, a true strain $0.10, \mathbf{b}$ true strain 0.36 , c true strain 0.69 , $\mathbf{d}$ true strain 1.2 at $0.5 \mathrm{~s}^{-1}$ and RT

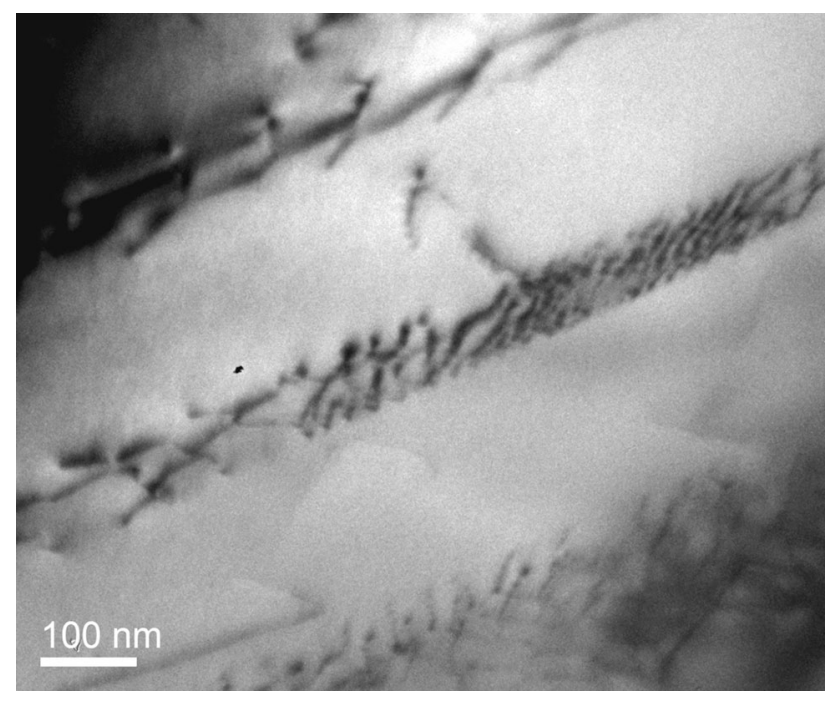

Fig. 4 TEM micrographs of Inconel X-750 alloy, compressed to 0.05 at $0.5 \mathrm{~s}^{-1}$, showing the planar arrangement of dislocations

$20 \mathrm{~nm}$ as shown in Fig. 8b at a higher magnification. Intersection between the dislocations and the deformation twins is observed in the Fig. 8b, and the diffraction pattern indexed along the [011] zone axis is shown in Fig. 8c.
The microstructure characteristic at large strain regime is one target of the paper. At the true strain of 1.2, the density of the deformation twins was higher and the distance between each other was shorter than that at true strain of 0.69 , as shown in Fig. 9a. It is worth noticing that the intersection between deformation twins is observed and the typical morphology is shown in Fig. 9b. Four distinct clusters of deformation twins appeared as shown in Fig. 9b, and Fig. 9c shows the microstructures of clusters $\mathrm{C}$ and D in detail at higher magnification. The neighboring clusters of deformation twins shown in Fig. 9b, c, imply that the deformation twins can form at different areas in a grain and deform the grain during their development, forming the clusters of deformation twins in different directions, causing the intersection between them. The deformation twins as shown in Figs. 8 and 9 and the deformation markings shown in Fig. 3c, d appeared simultaneously at stage IV when the strain exceeded 0.51 , and the deformation markings might be the trace of deformation twins on the observed surface. Conversely, the deformation markings appeared at stage IV implies that a new deformation mechanism takes place at the final stage of deformation, which might be the deformation twins. 

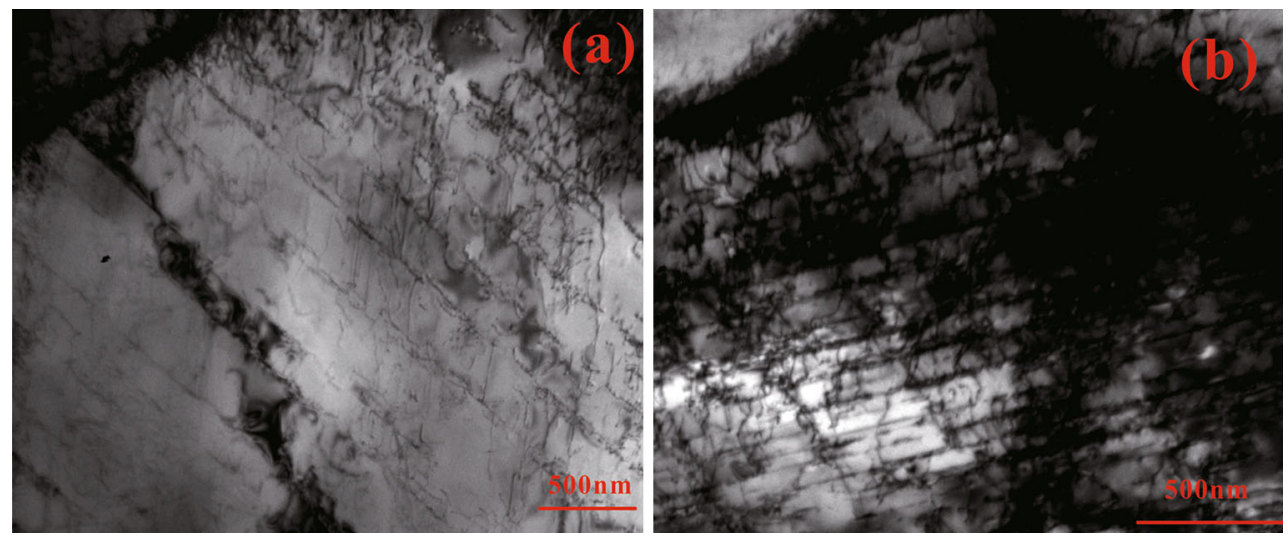

Fig. 5 Microstructures of Inconel X-750 alloy compressed to 0.1: a planar dislocation arrays or slip bands, b intersection of planar dislocation arrays

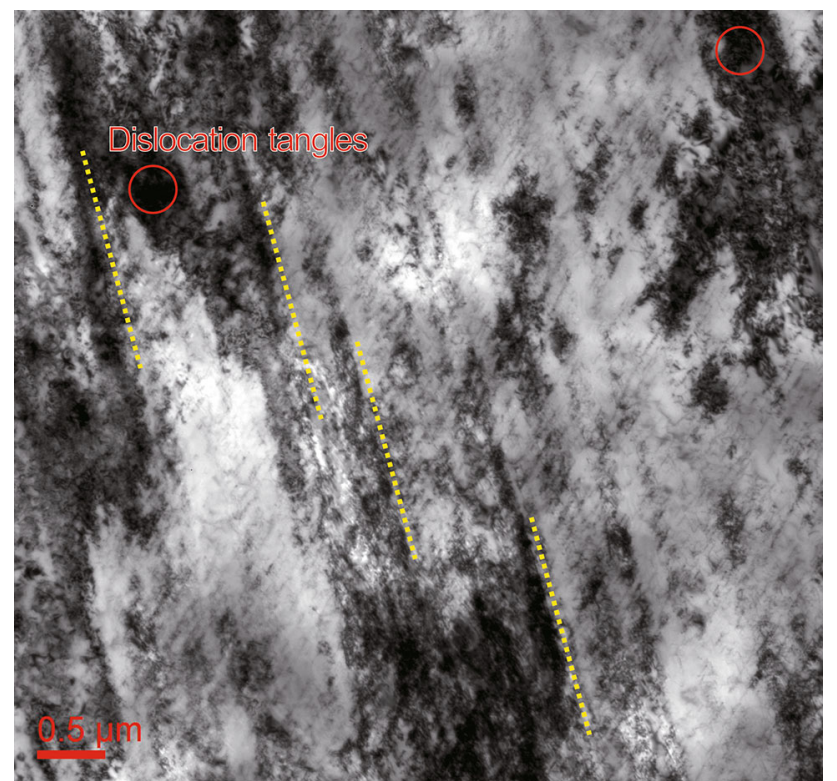

Fig. 6 TEM micrograph of the specimen compressed to a strain of 0.21 showing well-developed slip bands, and the dislocation tangles are shown in the circle regions

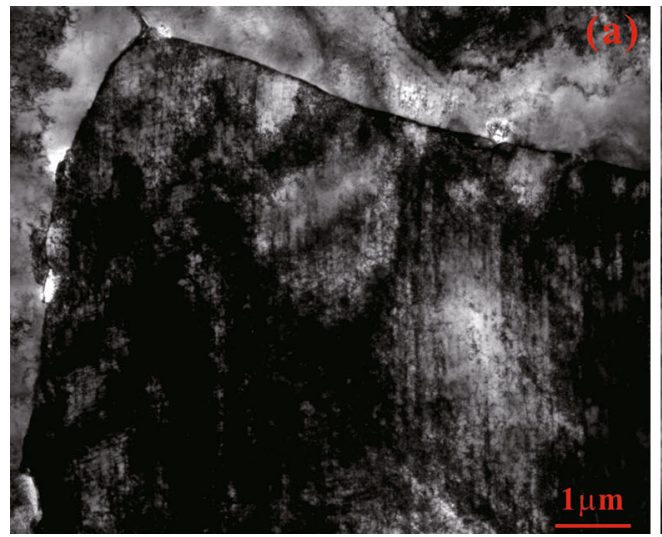

\section{Discussion}

For the materials with high SFE, dislocation slip dominates the plastic deformation, and as a result, the strain hardening rate can be described based on the single parameter, i.e., the dislocation density $\rho$. In this regard, the net of dislocation storage with imposed plastic strain $\left(\varepsilon_{\mathrm{p}}\right)$ can be written as [7, 29-31]:

$\frac{\mathrm{d} \rho}{\mathrm{d} \varepsilon_{\mathrm{p}}}=M\left(k_{1} \sqrt{\rho}-k_{2} \rho\right)$,

where $M$ is the Taylor factor and $k_{1}$ and $k_{2}$ are the parameters related to the athermal strain hardening limit and dynamic recovery, respectively. Owing to the simple strengthening mechanism by dislocation slip, the strain hardening rate decreases monotonically with increasing strain. Deviations from this behavior, however, have been recorded in some fcc alloys with low SFE, such as $\mathrm{Cu}-\mathrm{Al}$ alloys [4, 7-10], austenitic stainless steels [5] and twinning-induced plasticity steels [11], which can be mainly attributed to the occurrence of deformation twins. In these

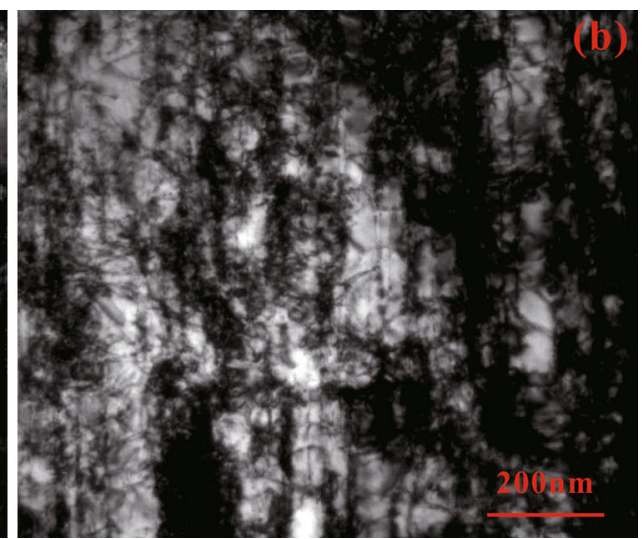

Fig. 7 TEM images of sample deformed to a strain of 0.36, showing a highly dense dislocations and narrower planar arrangement of dislocations, $\mathbf{b}$ the planar arrangement of the dislocations partially destroyed 

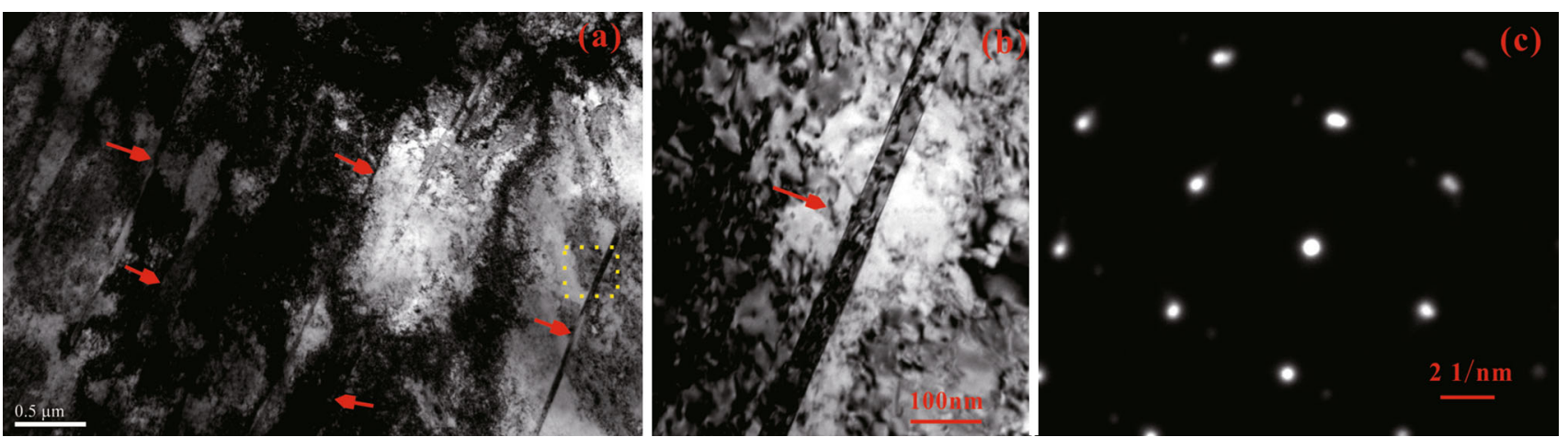

Fig. 8 Deformation twins at the true strain of 0.69 , a parallel deformation twins, b high magnification of the deformation twins in Fig. 8a, c $<011>$ axis diffraction pattern of twinned area
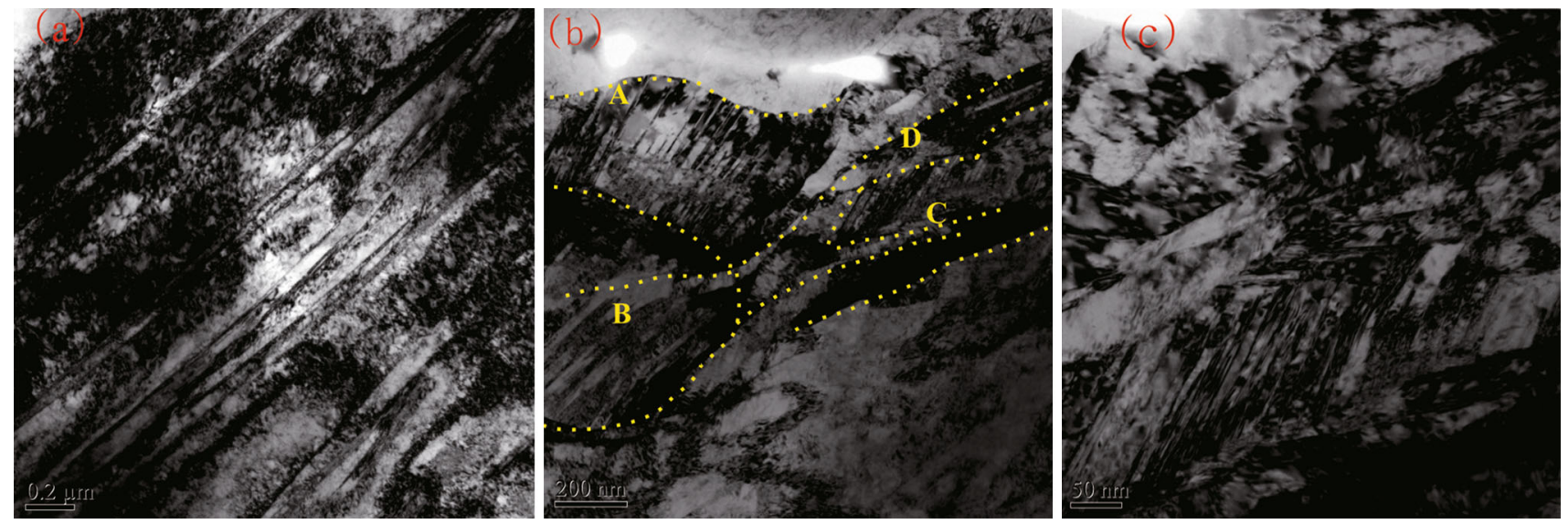

Fig. 9 Typical deformation twins in the sample deformed up to a true strain of 1.2, a parallel deformation twins, $\mathbf{b}$ cluster of deformation twins, c cluster twins in area $C, D$ in Fig. $9 \mathrm{~b}$ at higher magnification

cases, the continuous decrease in work hardening rate $\theta$ with the increase in strain was interrupted by an athermal strain hardening stage or stage II, and it is usually believed that the occurrence of athermal strain hardening stage is related to the low SFE value. According to the above discussion, the work hardening rate of Inconel X-750 alloy in the present paper should decrease monotonically as that of copper because the SFE of the alloy is as high as about $90 \mathrm{~mJ} / \mathrm{m}^{2}$ [21]. Four stages of strain hardening, however, were observed, and the decreasing tendency of the strain hardening coefficient is largely held back as shown in Fig. 1b, which is more similar to that of low-SFE alloys such as MP35 $\mathrm{N}$ and $\alpha$-brass and distinctively different from that of copper [2].

The four stages of work hardening plots have been attributed to the deformation twins at the onset of stage II and development during the subsequent deformation $[2,4,5,32]$. However, in the present paper, the planar dislocation configuration, instead of deformation twins, was observed at the initial of the work hardening stage II or the athermal hardening stage (Fig. 5). Further deformation to a strain of 0.21 , high-density dislocations were observed in the planar arrangements and some dislocation tangles were observed as shown in the circle regions in Fig. 6. When the strain went into stage III at the strain regime from 0.21 to 0.51 , the amounts of planar dislocations were increased and some of them were partially destroyed and deformation twins were absent (Fig. 7). It is interesting that the plastic deformation of Inconel X-750 alloy is caused by dislocation planar slip at the first three stages as that of high-SFE alloys, while its work hardening rate versus $\varepsilon_{\mathrm{p}}$ or $\left(\sigma-\sigma_{\mathrm{YS}}\right)$ plots resemble that of low-SFE alloys. Similar results have been obtained in Inconel 625 alloy, and the work hardening characteristic has been attributed to the short-range ordering (SRO) of the Ni-Cr-based alloys. In $\mathrm{Ni}-\mathrm{Cr}$ alloys, extensive formation of SRO was reported in the literature [33, 34]. It is well known that the pass of the first Shockley partial through the ordered lattice destroys this SRO, producing some extra energy, which is thermodynamically unfavorable. Then, when a dislocation source is active, all the dislocations prefer to slip on the plane to minimize the exposed extra energy, which, in turn, brings about the planar configuration of the dislocations. Formation of mechanical twins in fcc crystals requires passage of 
partial dislocations on all parallel closely packed planes of the matrix [1]. However, SRO may hinder the mechanical twins for the same reason that the motion of the dislocation on every fresh slip plane increases the lattice energy due to destruction of local ordering in each closely packed plane [13]. Due to strain constraint in polycrystals, a slip system change (secondary slip) is expected to provide new conjugate pairs, leading to extensive formation of LC locks. The LC locks act as the barrier to dislocation slip and raise the work hardening rates, which causes the formation of plateau of stage II.

With a higher strain level in stage III, partial dislocations, however, receive enough stress to overcome the lattice frictional stress and pass these obstacles, as shown in Fig. 7b. In addition, at this strain level, several sources of the dislocations are active, which push the SRO regions to collapse and provide easier cross-slip. These explain why a second falling regime of strain hardening is observed at the stage III.

As discussed in the microstructure characterization part, the deformation twins were formed when the strain exceeded 0.51 as shown in Figs. 8 and 9. It is well known that twin boundaries act as strong barriers against slip propagation. In essence, the formation of these deformation twins shortens the free slip distance of the dislocations [6] and makes the strain hardening rate stop falling again, leading to the appearance of stage IV. The role of deformation twins, however, is found to be more than just as barriers of the dislocation slips. The deformation twins were involved in the plastic deformation and occupied a relatively large part of the plastic deformation, because the deformation twins were distributed densely as shown in Fig. 9a. In addition, the clusters of the deformation twins were formed in different directions within a grain, indicating that the deformation twins could be formed at different regions of a grain (Fig. 9c). As a result, the stress concentration was relaxed by the operation of new twin systems. No cracks were observed in the specimens deformed at all conditions, and it is reasonable to be attributed to the twinning in large amounts.

It is unexpected that the deformation twins were formed in Inconel X-750 alloy, since it was absent in Inconel 625 even when the strain was as high as 0.65 [13]. Embury et al. [35] showed that the occurrence of a slip system change is a necessary condition for activation of deformation twinning. Besides SFE, grain rotation is a key factor for the operation of a slip system for twinning. Compared with Inconel X-750 alloy, the additions of Mo and $\mathrm{Nb}$ are much higher, and the matrix of Inconel 625 alloy naturally has a higher strength due to the higher solution strengthening addition. As a result, the crystal lattice is difficult to be deformed or bent, and slip system for twinning is difficult to be activated. The planner dislocation arrangement was easy to be destroyed as shown in Figs. 6 and 7, and the deformation twins were heavily bent as shown in Fig. 9. Compared with Inconel X-750 alloy, the planar dislocation configuration kept in a straight form even when the strain was as high as 0.65 in Inconel 625 alloy [13]. Perhaps for this reason, the deformation twin was formed in Inconel X-750 alloy when the strain was high enough.

\section{Conclusions}

1. The work hardening rate $\theta$ versus true strain curve of Inconel X-750 alloy resembles that of low-SFE alloys with distinct four stages.

2. Inconel X-750 alloy deformed by dislocation glide with planar arrangement at stages I, II and III, and twinning at stage IV. The deformation markings appeared simultaneously with the formation of deformation twins and might be the trace of twins on the observed surfaces. The clusters of twins in different directions were formed within a grain when the strain was as high as 1.2.

3. The planar arrangements of the dislocations were responsible for the occurrence of the plateau of stage II, and the twinning was responsible for the occurrence of stage IV of Inconel X-750 alloy with a nearly constant work hardening rate.

\section{References}

[1] J.W. Christian, S. Mahajan, Prog. Mater Sci. 39, 1 (1995)

[2] S. Asgari, E. El-Danaf, S.R. Kalidindi, R.D. Doherty, Metall. Mater. Trans. A 28, 1781 (1997)

[3] S.R. Kalidindi, Int. J. Plast. 14, 1265 (1998)

[4] A. Rohatgi, K.S. Vecchio, G.T. Gray III, Metall. Mater. Trans. A 32, 135 (2001)

[5] F. Hamdi, S. Asgari, Metall. Mater. Trans. A 39, 294 (2008)

[6] I. Gutierrez-Urrutia, D. Raabe, Acta Mater. 59, 6449 (2011)

[7] Y.Z. Tian, L.J. Zhao, N. Park, R. Liu, P. Zhang, Z.J. Zhang, A. Shibata, Z.F. Zhang, N. Tsuji, Acta Mater. 110, 61 (2016)

[8] Y. Tian, L. Zhao, S. Chen, D. Terada, A. Shibata, N. Tsuji, J. Mater. Sci. 49, 6629 (2014)

[9] R. Liu, Z. J. Zhang, L. L. Li, X. H. An, Z. F. Zhang, Sci. Rep. 5 (2015)

[10] Y. Tian, L. Zhao, S. Chen, A. Shibata, Z. Zhang, N. Tsuji, Sci. Rep. 5 (2015)

[11] O. Bouaziz, S. Allain, C.P. Scott, P. Cugy, D. Barbier, Curr. Opin. Solid State M. 15, 141 (2011)

[12] R. Mulford, U. Kocks, Acta Metall. 27, 1125 (1979)

[13] P. Behjati, S. Asgari, Mater. Sci. Technol. 27, 1858 (2011)

[14] J. Del Valle, A. Picasso, R. Romero, Acta Mater. 46, 1981 (1998)

[15] W.J. Mills, L.A. James, Fatigue Fract. Eng. Mater. Struct. 3, 159 (1980) 
[16] W. Mills, Metall. Trans. A 11, 1039 (1980)

[17] D.M. Symons, A.W. Thompson, Metall. Mater. Trans. A 28, 817 (1997)

[18] Y. Wang, Q. Pan, Y. Song, C. Li, Z. Li, Mater. Des. 51, 154 (2013)

[19] M. Pandey, D. Taplin, P.R. Rao, Mater. Sci. Eng. A 118, 33 (1989)

[20] G.R.X. de Souza, S.B. Gabriel, J. Dille, D.S. dos Santos, L.H. de Almeida, Mater. Sci. Eng. A 564, 102 (2013)

[21] R. Mulford, Acta Metall. 27, 1115 (1979)

[22] H. Mirzadeh, J.M. Cabrera, A. Najafizadeh, Acta Mater. 59, $6441(2011)$

[23] P. T. Hua, W. H. Zhang, W. R. Sun, L. J. Huang, S. C. Li, in Materials Science Forum (Trans Tech Publ, 2014), pp. 438

[24] R. Reed-Hill, W. Cribb, S. Monteiro, Metall. Mater. Trans. B 4, 2665 (1973)

[25] B.K. Choudhary, J. Christopher, Mater. Sci. Eng. A 651, 486 (2016)
[26] J. Christopher, B.K. Choudhary, Int. J. Pres. Ves. Pip. 146, 151 (2016)

[27] J. del Valle, R. Romero, A. Picasso, Mater. Sci. Eng. A 319, 643 (2001)

[28] T.G. Ference, S.M. Allen, Metall. Trans. A 17, 2239 (1986)

[29] B.K. Choudhary, J. Christopher, Mater. Sci. Eng. A 636, 269 (2015)

[30] B.K. Choudhary, J. Christopher, Metall. Mater. Trans. A 44, 4968 (2013)

[31] J. Christopher, B.K. Choudhary, M.D. Mathew, T. Jayakumar, Mater. Sci. Eng. A 575, 119 (2013)

[32] E. El-Danaf, S.R. Kalidindi, R.D. Doherty, Metall. Mater. Trans. A 30, 1223 (1999)

[33] N. Clément, D. Caillard, J.L. Martin, Acta Metall. 32, 961 (1984)

[34] A. Marucco, B. Nath, J. Mater. Sci. 23, 2107 (1988)

[35] J. Embury, M. Szczerba, Z. Basinski, Met. Mater. Soc. 331 (1994) 